\title{
EVALUATION OF SURGICAL TREATMENT OF FRACTURES OF THORACOLUMBAR SPINE WITH THIRD-GENERATION MATERIAL FOR INTERNAL FIXATION
}

\author{
Adalberto Bortoletto', Luiz Cláudio Lacerda Rodrigues², Marcelo Hide Matsumoto³
}

\section{ABSTRACT}

Objective: To evaluate the functional results from patients with surgical fractures in the thoracolumbar spine. Method: A prospective study including 100 patients with spinal fractures in the thoracic and lumbar segments was conducted. The lesions were classified in accordance with the AO system, and the patients were treated surgically. The presence of early kyphosis and its evolution after the surgical intervention, and the presence of postoperative pain and its evolution up to the $24^{\text {th }}$ week after the surgery, were evaluated. We compared our data with the literature. Results: One hundred surgical patients were analyzed, of which 37 were type A, 46 were type B and 17 were Type C. Patients who presented Frankel A kept their clinical status, but patients with Frankel B or higher evolved with some improvement. The average improvement in pain based on a visual analog scale was more than four points. All the patients were able to return to their daily routine activities, although we did not take the return to work to be an assessment criterion. Conclusion: Despite controversy regarding the indications for surgery in cases of fractured spine, we believe that the method that we used was satisfactory because of the good results and low complication rate. However, more randomized prospective studies with longer follow-up are needed in order to evaluate this type of fixation.

Keywords - Spinal Fractures/classification; Spinal Fractures/surgery; Spinal Cord Injuries; Treatment Outcome

\section{INTRODUCTION}

The management for patients with fractures of the thoracolumbar spine is a matter of controversy and has, over recent decades, been the topic of studies and investigations in many specialized centers. This research has produced new concepts and procedures of greater efficiency for early rehabilitation of such patients. Nonetheless, different opinions exist regarding the best approach.

The use of third-generation material started with Cotrel and Dubousset ${ }^{(1)}$ in 1985, simultaneously with dissemination of the concepts of rigid stabilization and three-dimensional correction.
The internal fixator was presented for the first time by Dick in $1987^{(2)}$. This was based on the Margel system and consisted of Shanz pins connected to a bar by a system that allowed movement in the longitudinal direction and also allowed angular movement. Long pins enabled manual reduction, and these were cut after fixation of the system.

The aim of this study was to analyze 100 cases of patients with fractures of the thoracolumbar spine who were treated surgically with third-generation material of internal fixator type, in the eastern zone of São Paulo, based on clinical and radiological criteria. The clinical parameters were correlated with the

\footnotetext{
1 - Head of the Spinal Pathology Group, Department of Orthopedics, Hospital Santa Marcelina, Eastern Zone, São Paulo, Brazil.

2 - Attending Physician, Spinal Pathology Group, Department of Orthopedics, Hospital Santa Marcelina, Eastern Zone, São Paulo, Brazil.

3 - Head of the Orthopedics and Traumatology Service, Hospital Santa Marcelina, Eastern Zone, São Paulo, Brazil.
}

Work performed in the Department of Orthopedics and Traumatology, Hospital Santa Marcelina.

Correspondence: Luiz Cláudio Lacerda Rodrigues - Departamento de Ortopedia - Hospital Santa Marcelina - Rua Santa Marcelina, 177 - Itaquera - 08270-070

São Paulo, SP. E-mail: luizclr@terra.com.br

Work received for publication: August 1, 2010; accepted for publication: December 23, 2010 
presence of residual deformity, and the progression of such deformities was evaluated during the postoperative follow-up.

\section{MATERIALS AND METHODS}

This was a prospective study in which all patients with fractures of the thoracolumbar spine who agreed to participate were included. The evaluation was concluded 24 weeks after assessing the last patient included.

Prospective analysis was conducted on 100 patients who underwent operations between January 2006 and July 2009 at Hospital Santa Marcelina, in the eastern zone of São Paulo, to treat fractures of the thoracolumbar spine. The inclusion criteria were the presence of fractures of the thoracolumbar spine that had occurred less than 10 days earlier, an indication for surgery and signing of an informed consent statement in accordance with the study protocol. All the patients underwent radiographic and computed tomography (CT) examinations. Patients presenting neurological deficits also underwent magnetic resonance imaging (MRI). All the patients were followed up for a minimum of 24 weeks.

During the follow-up, the patients underwent radiographic examinations in an upright standing position to control for kyphosis. This was assessed by means of the Cobb method ${ }^{(3)}$ before the operation, during the immediate postoperative period, one month after the operation and six months after the operation. In measurements for regional evaluations, the parameters were the end plate of the vertebra above the fractured vertebra and the distal plate of the vertebra below the fractured vertebra.

The classification used was as recommended by AO. It was observed that there were 37 type A fractures, 46 type $B$ and 17 type $C$. The predominant level was L1, in 41 cases, followed by L 2 in 17 cases and $\mathrm{T} 12$ in 15 cases. The total distribution is represented in Figure 1.

The main cause of the fractures was falls, in 78 cases. Twelve cases resulted from car accidents, nine were due to motorcycle accidents and one case was due to being run over. The Frankel scale was used to assess the neurological condition ${ }^{(4)}$.

The results were assessed based on comparisons of

Rev Bras Ortop. 2011;46(3):299-304

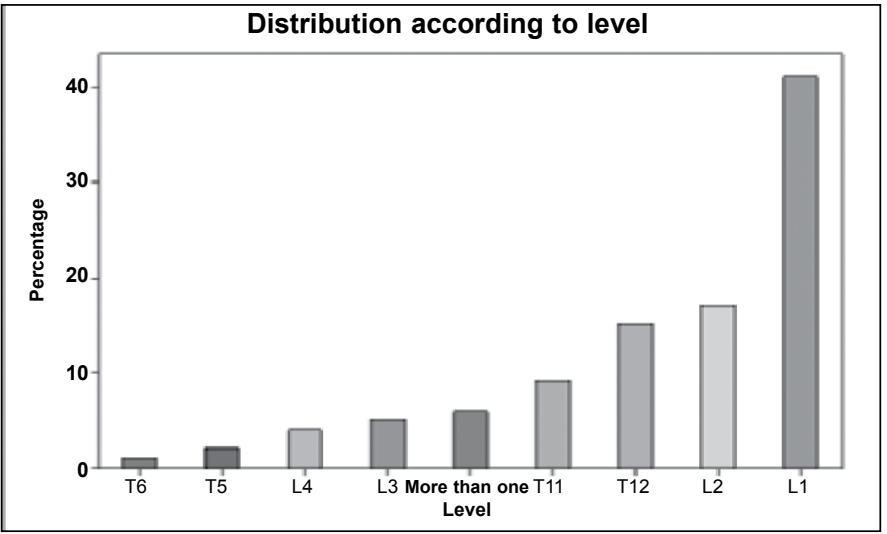

Figure 1 - Distribution of fractures according to level.

residual pain using the VAS classification, in relation to the presence of kyphosis, the patient's sex and the type of trauma.

All the patients were operated by the same team, and the Synthes ${ }^{\circledR}$ third-generation internal fixator system was used for all cases.

\section{RESULTS}

From evaluations of neurological condition, none of the cases worsened. All conditions graded as Frankel B, C and D improved. The proportion of cases at L1 level was significantly greater than the cases at other levels (chi-square test with $\mathrm{p}<0.001$ ). The incidence at L2 and T12 levels was similar (chi-square test with $p=0.724)$. There were no significant differences from T11 with other levels in smaller proportions $(p=0.101)$.

There was no statistical difference between the proportions of type A and type B fractures (chi-square test; $p=0.323$ ), but the percentage of type $C$ fractures was significantly lower (chi-square test; $p=0.001$ ). The proportion of Frankel E was significantly greater (chi-square test; $p<0.001$ ), while there were no significant differences between the others (chi-square test; $\mathrm{p}=0.484$ ) (Figure 2).

The mean pain assessment based on VAS was 7 (ranging from 5 to 9) before the operation. One month after the operation, the mean pain level was 6 (ranging from 2 to 7) and, six months after the operation, it was 4 (ranging from 0 to 6 ). The initial mean kyphosis was $56^{\circ}$ (ranging from $29^{\circ}$ to $80^{\circ}$ ). The mean immediate postoperative $\mathrm{Cobb}$ was $28^{\circ}$ (ranging from $15^{\circ}$ to $50^{\circ}$ ). Six months after the operation, the mean Cobb was $32^{\circ}$ (ranging from $20^{\circ}$ to $52^{\circ}$ ). 


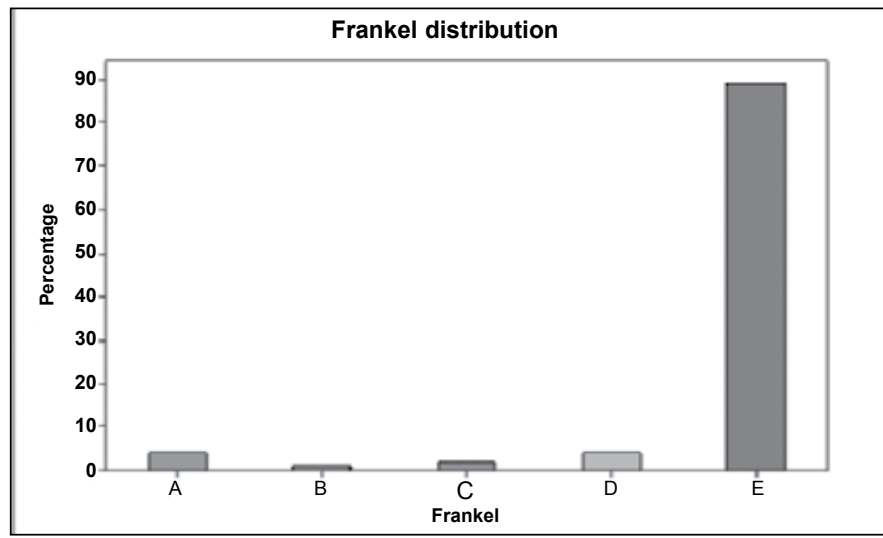

Figure 2 - Correlation of the patients' neurological deficits.

There were seven cases of infection, which made it necessary to remove the material in five of these cases. One case of removal of material was in a patient with a Chance fracture who, because of multiple skin abrasions, was not in a condition to use a vest. We decided to use instrumentation without arthrodesis in this case alone, with removal six months later. The mean number of screws used was eight (ranging from four to 16).

In pain data comparisons, we observed that repeated-measurement ANOVA did not show any significant differences between the sexes at any time (intergroup comparison; $\mathrm{p}=0.461$ ), but there were differences within each sex between times (intragroup comparison; $\mathrm{p}<0.001$ ) (Figure 3).

In kyphosis comparisons using repeated-measurement ANOVA, there were no differences between the sexes at any time (intergroup comparison; $p=0.958$ ), but there were differences between times (intragroup comparison; $\mathrm{p}<0.001)$. The immediate postoperative Cobb was significantly smaller than the initial Cobb, but then started to increase again after six months (Figure 4).

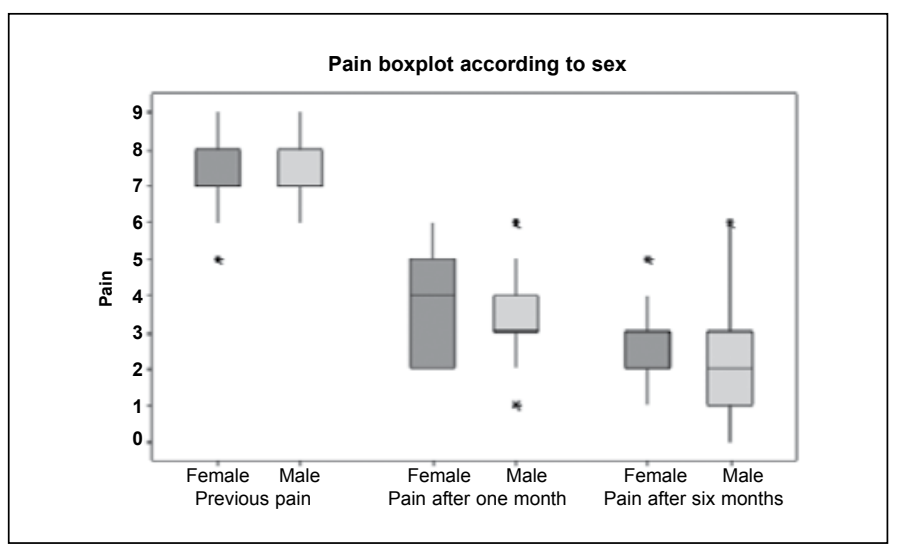

Figure 3 - Evolution of the painful condition in relation to sex.

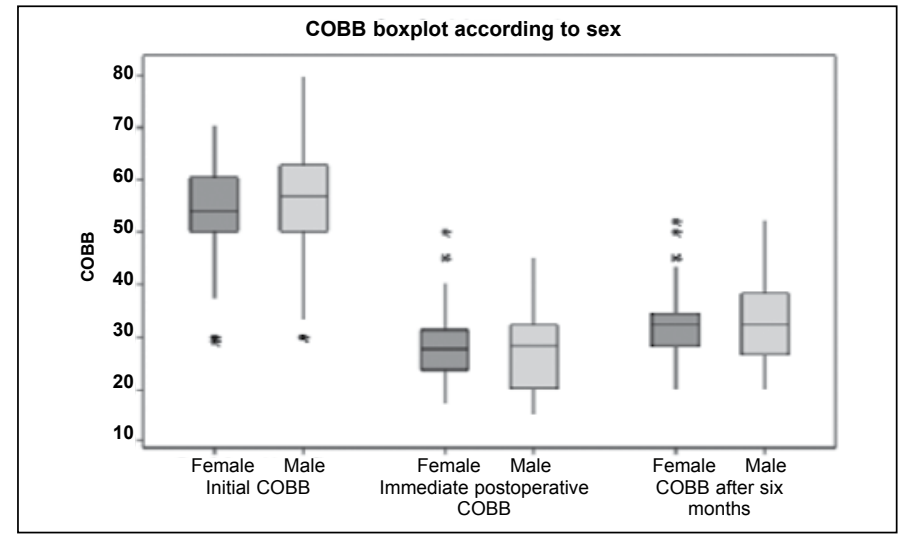

Figure 4 - Comparison between Cobb and sex, and its evolution.

We found significant differences between the sexes, i.e. females had significantly more infections than shown by males (chi-square test; $p=0.030$; or Fisher exact test; $p=0.043)$. We found five cases of infection in females.

Comparing ages according to type of fracture, cause of accident and Frankel, we observed the following. There were no significant differences between the mean ages of the three groups according to type of fracture (ANOVA test; $p=0.063$ ). There were no significant difference between the mean ages of the three groups according to the cause of the accident (ANOVA test; $p=0.156$ ). There were no significant differences between the age distributions of the various groups, in comparisons of neurological deficits (Kruskal-Wallis test; $p=0.931$ ). Comparison between age and Cobb angle showed that there was no relationship. There was also no correlation between age and patients' pain. There were no significant differences in the proportions of different types of fractures between the different types of causes of accidents (chi-square test; $p=0.987$ ) (Figure 5).

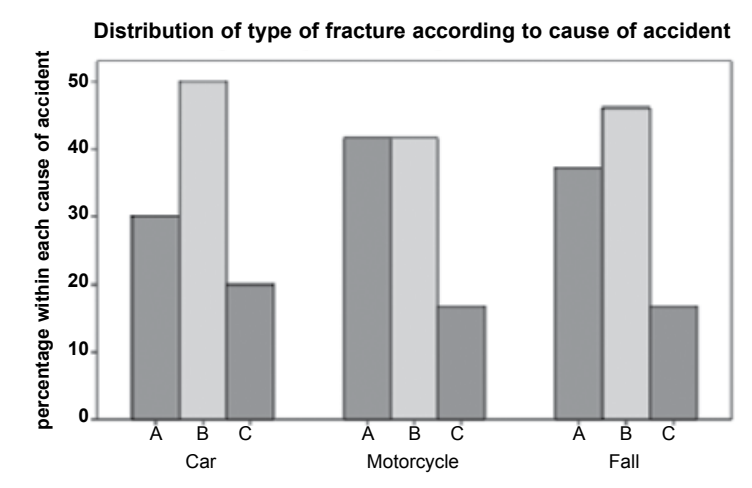

Figure 5 - Comparison between type of fracture and cause of accident. 
There were 89 patients with Frankel E, four with Frankel D, two with Frankel C, one with Frankel B and four with Frankel A. There were significant differences in the proportions of the different types of Frankel between the different types of fractures (chisquare test; $p=0.001$ ). Investigation of where the significant differences were showed the following: Frankel type A was significantly greater in fracture type $C(p=0.017)$; Frankel type $E$ was significantly greater in fracture types A and B than in $\mathrm{C}(\mathrm{p}<$ 0.001); while the other Frankel types did not present any significant differences (Figure 6).

Based on repeated-measurement ANOVA, differences between the types of fracture were seen as all times (intergroup comparison; $p=0.001$ ). Type A fractures had significantly lower pain values than shown by type $C$ fractures, at all times $(p=0.001)$ (Figure 7).

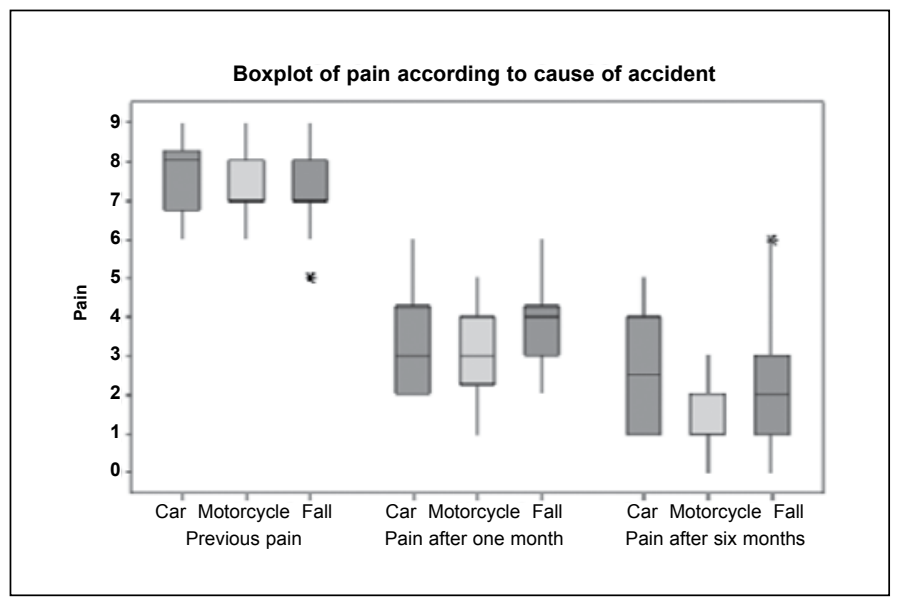

Figure 6 - Comparison between cause of accident and evolution of pain.

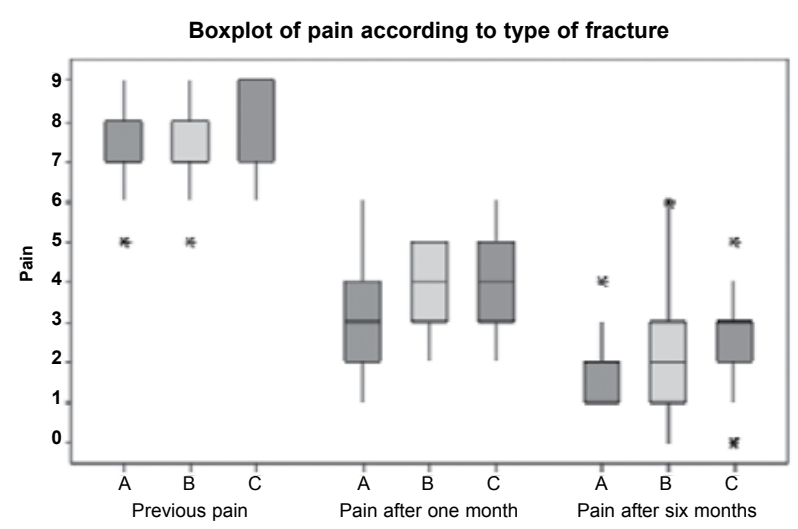

Figure 7 - Comparison between the type of fracture and the evolution of pain.
Using the same repeated-measurement tool, differences between fracture types were seen only during the immediate postoperative period $(p=0.033)$. Type A fractures only had significantly lower Cobb values than shown by type B fractures during the immediate postoperative period $(\mathrm{p}=0.028)$. Comparing the times, there were differences between all the times for all the types of fractures $(p<0.001)$.

There was a significant Spearman correlation for pain at different times, i.e. patients who felt more pain initially continued to feel more pain at other times.

Infection was seen to be present in seven patients (five females and two males). The implants had to be removed in the two male cases and three of the females, and these five patients had to use postoperative orthoses.

There were no differences between patients with and without infection at any time (intergroup comparison; $p=0.121$ ), but we found a difference between the times (intragroup comparison; $p<0.001$ ). There were significant differences between all the times (also $\mathrm{p}<0.001$ ) (Figure 8).

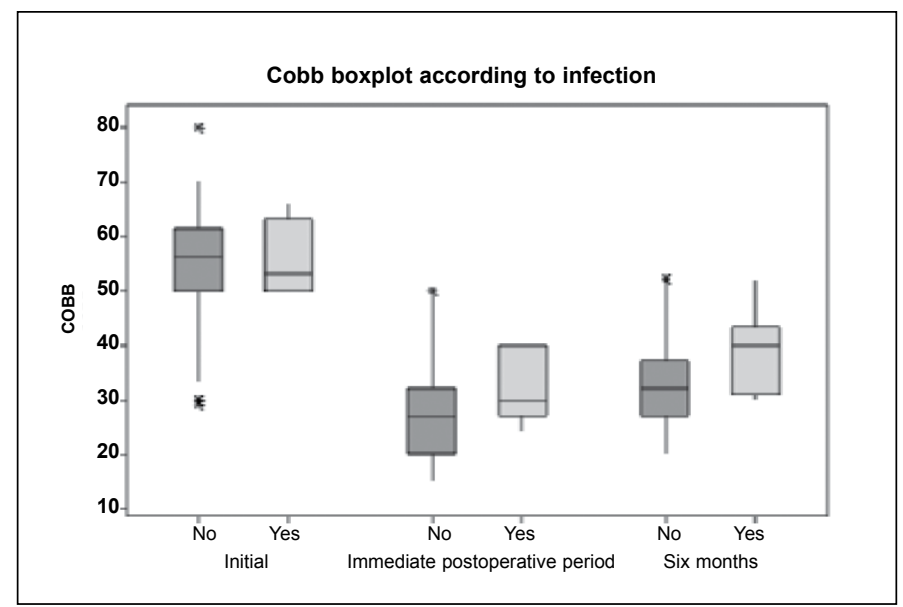

Figure 8-Correlation of Cobb angle with presence or absence of infection at the surgical site.

\section{DISCUSSION}

There are few studies evaluating this type of fixation in the literature. This study did not aim to be a guide for treating fractures but, rather, simply presents our results, in which we evaluated the radiological evolution, with periodic measurements of kyphosis and postoperative pain, which were compared between the sexes, types of fractures and patients' functional results. 
The first studies using pedicle screws were described by Fuentes and Defino in $1990^{(5)}$. However, they used simple pedicle screws in their 12 patients. They reported that postoperative orthoses did not need to be used for any of their patients. Our range of Cobb angles was $4^{\circ}$ during the immediate postoperative period, for evolution over six months with an internal fixator, and remaining one degree lower than the mean shown in the American and European literature ${ }^{(6,7)}$.

Siebenga et $\mathrm{al}^{(8)}$ presented some data showing that instrumentation with pedicle screws preserved the fractured vertebra but was unable to preserve the disc space. They observed that the disc height diminished and that a posterolateral graft aided fusion but did not influence the sequence of events.

Comparing our data with the literature ${ }^{(6,7)}$, there was no neurological worsening in any case. There were improvements on the Frankel scale among the patients assessed as B, C and D, but we did not observe any improvement in the patients with Frankel A. This shows the efficacy of the instrument and the rigid immobilization that it presents, since stabilization enables early rehabilitation and protection of the neural tissue, which is no longer in a distressed state (Figures 9A, 9B, 9C and 9D).

Unlike in the data presented by Wood et $\mathrm{al}^{(9)}$, who correlated the presence of kyphosis and the functional results, we did not find any correlation between kyphosis and postoperative pain based on serial VAS assessments, even though the mean loss of kyphosis was $6.7^{\circ}$. Studies showing this distortion were pu- blished as early as $1987^{(10-12)}$, but so far no study has explained this abnormality.

We compared our pain assessments with those of other studies, and noted that reductions in pain have been reported in several studies, with significant decreases in VAS levels ${ }^{(9,13-16)}$.

Contrary to some studies, our study did not reveal any neurological worsening as reported by others, especially during the immediate postoperative pe$\operatorname{riod}^{(13,17)}$. Our patients who presented Frankel B, C and $\mathrm{D}$ achieved increases of one degree on the Frankel scale.

In the studies by Knop et $\mathrm{al}^{(18)}$ and Marti Garin et $\mathrm{al}^{(19)}$, it was reported that the presence of infection might give rise to the need to remove the synthesis material. In our study, the presence of infection led to removal of the synthesis material in five patients. All of these cases then presented resolution of the secretion. We also had two cases of infection that presented improvements in the infectious process after open cleaning, culturing and correctly applied antibiotic. In one specific case, the material had to be removed because the patient presented a type B21 fracture (Chance), Because of this patient's poor skin condition at the time of the trauma, we decided to use instrumentation without arthrodesis in this case alone. This was removed six months later with an excellent clinical and radiological result. All the other patients received a graft from the posterolateral iliac.

Another complication described in the literature is pain at the site of graft harvesting ${ }^{(20,21)}$, with reports that there is significant incidence of pain at the donor
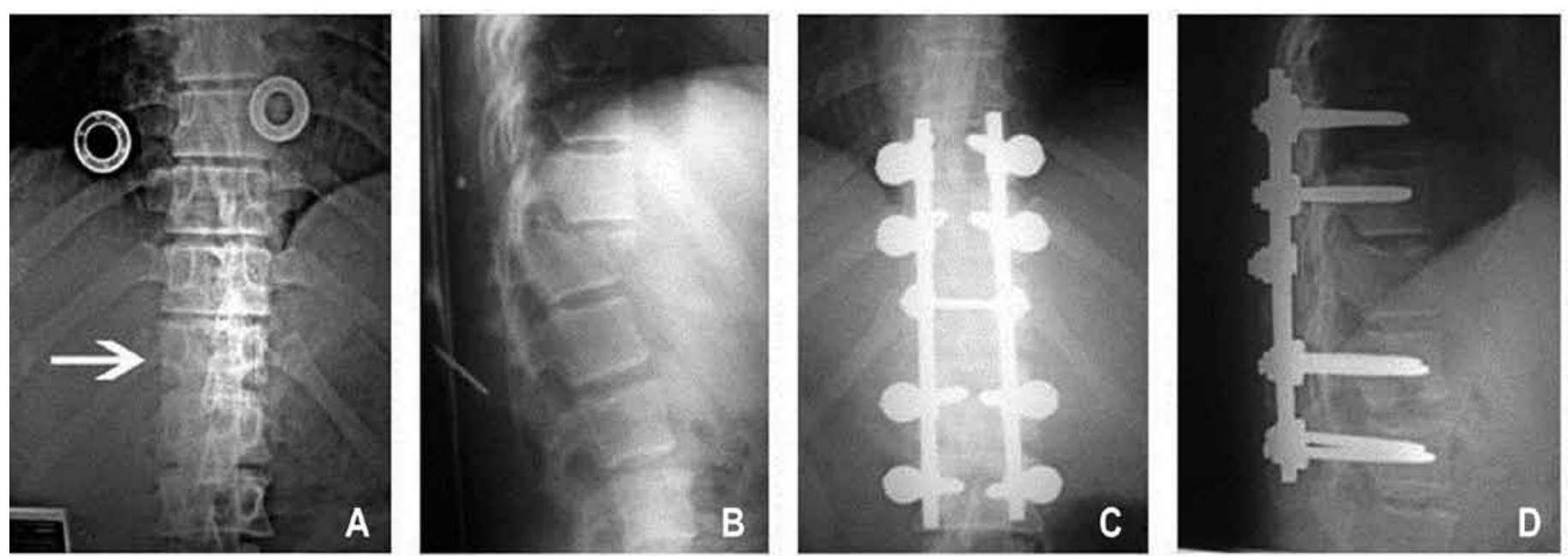

Figures 9A-D - Case of type $C$ fracture viewed during the immediate postoperative period. 
site. We harvested bone grafts from almost all of our patients: they reported the presence of postoperative pain with improvement over the evolution of the cases. The above authors also reported that there was a possibility of infection in the donor region: there was one case that evolved with infection in the iliac crest, for which 42 days of vancomycin was required to resolve the problem.

We did not assess return to work as a characteristic indicating a good result because only $32 \%$ of these patients actually returned to work. From the radiographic result and the pain assessment, these patients did not present any significant differences from the general mean and were within the maximum and minimum values.

\section{CONCLUSION}

It is known that thoracolumbar spinal trauma is related to high-energy traumatic events such as falls from a height or car accidents. These patients cannot be neglected in the emergency services, since all multiple-trauma patients are potentially spinal trauma patients until such a diagnosis can be ruled out.

For patients presenting fractures of the thoracolumbar spine, we suggest that the AO classification should be used for surgical indications, with early surgery for such patients. This diminishes the complications relating to hospitalization.

There is some controversy regarding surgical indications, but our favorable results and low complication rate have led us to think better of this procedure and its results. The results with an internal fixator showed significant correction of the kyphosis and a mean loss lower than has been presented in studies using simple pedicle screws. We conclude that internal fixators provide a safe method with good results, although we are aware that further controlled and randomized studies are necessary.

\section{REFERENCES}

1. Cotrel $\mathrm{Y}$, Dubousset J. New segmental posterior intrumentation of the spine. Orthop Trans.1985;9:118.

2. Dick $W$.The "fixateur interne" as a versatile implant for spine surgery. Spine (Phila Pa 1976). 1987;12(9):882-900.

3. Cobb JR. Outline for the study of escoliosis, Am Acad Orthop Surg Instr CourseLect 1948;5:261-75.

4. Frankel HL, Hancock DO, Hyslop G, Melzak J, Michaelis LS, Ungar GH, The value of postural reduction in the initial managemnet of closed injuries of the spine with paraplegia and tetraplegia, Part 1. Paraplegia. 1969;7(3):179-92.

5. Fuentes AE, Defino HL. Experiência inicial com o Instrumental de Cotrel-Dubousset. Rev Bras Ortop. 1995;30(3):119-24.

6. Stambough JL. Cotrel-Dubosset intrumentation and thoracolumbar spine trauma: a review of 55 cases. J Spinal Disord. 1994;7(6):461-9.

7. de Peretti F, Hovorka I, Cambas PM, Nasr JM, Argenson C. Short device fixation and early mobilization for burst fractures of the thoracolumbar junction. Eur Spine J. 1996;5(2):112-20.

8. Siebenga J, Leferink VJ, Segers MJ, Elzinga MJ, Bakker FC, Haarman $\mathrm{HJ}$, et al. Treatment of traumatic thoracolumbar spine fractures: a multicenter prospective randomized study of operative versus nonsurgical treatment. Spine (Phila Pa 1976). 2006;31(25):2881-90.

9. Wood K, Buttermann G, Mehbod A, Garvey T, Jhanjee R, Sechriest V, et al. Operative compared with nonoperative treatment of a thoracolumbar burst fracture without neurological deficit: a prospective, randomized study. J Bone Joint Surg Am. 2003;85:773-81.

10. Resch H, Rabl M, Klampfer H, Ritter E, Povacz P. [Surgical vs. conservative treatment of fractures of the thoracolumbar transition]. Unfallchirurg. 2000;103(4):281-8.

11. Briem D, Linhart W, Lehmann W, Bullinger M, Schoder V, Meenen NM, et al. Investigation of the health-related quality of life after a dorsoventral stabilization of the thoracolumbar junction. Unfallchirurg. 2003;106(8):625-32.
12. Butler JS, Walsh A, O'Byrne J. Functional outcome of burst fractures of the first lumbar vertebra managed surgically and conservatively. Int Orthop. 2005;29(1):51-4.

13. Denis F, Armstrong GW, Searls K, Matta L. Acute thoracolumbar burst fractures in the absence of neurologic deficit. A comparison between operative and nonoperative treatment. Clin Orthop Relat Res. 1984;(189):142-9.

14. Domenicucci M, Preite R, Ramieri A, Ciappetta P, Delfini R, Romanini L. Thoracolumbar fractures without neurosurgical involvement: surgical or conservative treatment? J Neurosurg Sci. 1996;40(1):1-10.

15. Leferink VJ, Keizer HJ, Oosterhuis JK, van der Sluis CK, ten Duis HJ. Functional outcome in patients with thoracolumbar burst fractures treated with dorsal instrumentation and transpedicular cancellous bone grafting. Eur Spine J. 2003;12(3):261-7.

16. Dai LD. Low lumbar spinal fractures: management options. Injury. 2002;33(7):579-82.

17. Mumford J, Weinstein JN, Spratt KF, Goel VK. Thoracolumbar burst fractures. The clinical efficacy and outcome of nonoperative management. Spine (Phila Pa 1976). 1993;18(8):955-70.

18. Knop C, Blauth M, Bastian L, Lange U, Kesting J, Tscherne H. [Fractures of the thoracolumbar spine. Late results of dorsal instrumentation and its consequences]. Unfallchirurg. 1997;100(8):630-9.

19. Marti Garin D, Villanueva Leal C, Bago Granell J. Stabilization of the lower thoracic and lumbar spine with the internal spinal skeletal fixation system and a cross-linkage system. First results of treatment. Acta Orthop Belg. 1992;58(1):36-42.

20. Ebraheim NA, Elgafy $H, X u R$. Bone-graft harvesting from iliac and fibular donor sites: techniques and complications. J Am Acad Orthop Surg. 2001;9(3):210-8.

21. Hill NM, Horne JG, Devane PA. Donor site morbidity in the iliac crest bone graft. Aust N Z J Surg. 1999;69(10):726-8. 